\title{
NARRATIVAS TRANSMEDIA EN LA COMUNICACIÓN DE LAS ONG. SÍ ME IMPORTA DE OXFAM INTERMÓN
}

\section{Transmedia Storytelling in the NGO Communication. Sí me importa by Oxfam Intermón}

\section{Laura MARTÍNEZ VALERO}

Universidad Rey Juan Carlos de Madrid, España

E-mail: lauvalero@hotmail.com

(iD) http://orcid.org/0000-0002-1171-0695

Fecha de recepción del artículo: 03/10/2016

Fecha de aceptación definitiva: 13/10/2016

\begin{abstract}
RESUMEN
Las narrativas transmedia se han utilizado tradicionalmente para expandir los universos narrativos de obras de ficción, como películas y series de televisión. Sin embargo, era cuestión de tiempo que su capacidad para explicar la realidad fuera descubierta y aprovechada por las organizaciones sociales para explicar las causas con las que trabajan y llegar a nuevas audiencias. Además, el nuevo entorno móvil pone a prueba la imaginación de las organizaciones para desarrollar productos que exploten al máximo las posibilidades de esta nueva forma de consumo. La campaña Si me importa, un proyecto transmedia de la ONG española Oxfam Intermón, reivindicó la importancia de la cooperación al desarrollo a través de las redes sociales, el cómic, el teatro, el arte contemporáneo y el cine.
\end{abstract}

Palabras clave: transmedia; ONG; Oxfam; social; narrativa; importa.

\begin{abstract}
Traditionally, transmedia storytelling has been used for spreading fiction narrative worlds, such as films and TV series. However, it was a matter of time that its ability for explaining the reality was discovered and utilised by social organizations to explain their causes and to reach new audiences. Moreover, the new mobile environment challenges the creativity of the organizations to develop products that make use of this new form of consumption. The Si me importa campaign, a transmedia project of the Spanish NGO Oxfam Intermón, reclaimed the importance of the international cooperation through social networks, comic, theatre, contemporary art and cinema.
\end{abstract}

Key words: transmedia; storytelling; NGO; Oxfam; social. 


\section{INTRODUCCIÓN}

El uso de diferentes media para transmitir un relato no es un fenómeno reciente. Se trata, de hecho, de una de las características más antiguas de la comunicación humana. Durante siglos hemos transmitido las mismas historias y mitos, primero de forma oral, luego escrita y en los últimos tiempos a través de películas, series y videojuegos. A ello hay que incorporar recientemente la cuarta pantalla o smartphone, capaz de aglutinar en su microsuperficie la mayoría de los formatos anteriores a su aparición. Nos encontramos en un momento en el que por primera vez el promedio de tiempo diario que los usuarios pasan en el móvil (177 minutos) supera el promedio de tiempo que las personas pasan delante de la televisión (168 minutos), según el Informe Ditrendia: Mobile en España y en el Mundo del año 2015.

En el ámbito transmedia, ya han pasado 13 años desde que Henry Jenkins introdujera por primera vez este término en el artículo Transmedia Storytelling. Moving characters from books to films to video games can make them stronger and more compelling. Hoy en día es un concepto muy utilizado, pero existe aún dificultad para definirlo. Según Carlos Alberto Scolari:

Nos encontramos en un terreno semánticamente inestable, caótico, donde resulta difícil hacer pie. En las conversaciones sobre las narrativas transmedia también suelen aparecer otros conceptos como cross-media, multimodalidad, multiplataforma o narrativa aumentada (Scolari 2013, p. 26).

Para Mara Balestrini el universo léxico que rodea a la narrativa transmedia ha acabado convirtiendo este término en «una buzzpord ${ }^{1}$ que generalmente se utiliza de una forma poco clara o más bien demasiado amplia, entrando en confusión con otros conceptos como crossmedia o multiplataforma» (Balestrini, 2011). En el presente artículo se considera que una definición muy completa sería la de María Vega, experta en desarrollo de contenidos transmedia:

Se trata de una forma de narrativa en la que las historias se cuentan a través de múltiples plataformas, cada una de ellas aportando algo nuevo y único al universo narrativo que se crea, constituyendo, además, diferentes puertas de acceso a ese universo para el usuario. Es crucial que todas esas plataformas puedan ser consumidas y entendidas independientemente, es decir, por sí solas tendrán sentido para los usuarios. El papel de estos en las narrativas transmedia es especialmente importante, ya que pasan a tener un rol mucho más activo, convirtiéndose en productor a la vez que consumidor, contribuyendo a la construcción de la narrativa (Murillo, 2014).

Hasta ahora la gran mayoría de libros, documentos, tesis y trabajos que se han realizado sobre este tipo de narrativas han estado centrados en el análisis de obras de ficción, como la saga Harry Potter, las películas The Matrix o Star Wars, la serie Juego de Tronos o las series españolas Águila Roja, El Ministerio del Tiempo o Carlos, rey emperador.

\footnotetext{
1 Buzzword: «palabras relacionadas con el campo de la comunicación que suenan importantes y técnicas, y que algunas personas usan fundamentalmente para impresionar a los legos en la materia» (American Heritage Dictionary).
} 
No obstante, también se han realizado interesantes proyectos transmedia basados en la realidad, especialmente en el campo del periodismo, pionero a la hora de buscar nuevas formas de narrar la realidad. Dos ejemplos ya clásicos son Proyecto Walsh (2011) y Malvinas 30 (2012) del productor e investigador argentino Álvaro Luzzi.

Dentro de este tipo de proyectos de corte periodístico, empiezan a destacar aquellos que, además de informar, apelan a la participación del usuario con un objetivo social. Así, le invitan a que defienda una causa, firme una petición o haga visible un tema. Buenos ejemplos de ello son el proyecto Mujeres en venta (2015) de la Universidad Nacional de Rosario o el Proyecto Rosa (2012) del medio colombiano La Silla V acía. El primero, además de denunciar la trata de mujeres en Argentina a través de fotografías, cómics o documentales, invita a denunciar hechos que puedan estar vinculados a la trata de personas con fines de explotación sexual. Para ello pone a disposición del usuario un mapa colaborativo en el que realizar denuncias anónimas. Además, conscientes del actual entorno móvil, han desarrollado su web para que sea responsive y han diseñado materiales específicos para ser consumidos desde los dispositivos móviles, como píldoras breves de vídeo con una duración máxima de 3 minutos a los que han llamado movisodios.

Por otro lado, el Proyecto Rosa de La Silla Vacía fue ganador del Premio Alemán de Periodismo y Desarrollo del año 2013. Se inició en agosto de 2012 con el fin de hacer visible y mantener con vida a Rosa Amelia Hernández, una líder que lucha por los derechos de las víctimas de la violencia y el desplazamiento forzado en Colombia. Además de difundir contenidos periodísticos, obras de arte, carteles y canciones, en el sitio web existe un apartado, Yo apoyo a Rosa, en el que se anima al consumidor a convertirse en prosumidor, productor y consumidor, y generar contenidos propios, como canciones, gráficos u obras audiovisuales para difundir de manera online u offline. Cabe destacar que, debido a su diseño con Adobe Flash, desde el año 2013 Proyecto Rosa no es compatible con las últimas versiones de Android, el sistema operativo móvil más extendido en todo el mundo, ni con el sistema iOS. Ello sin duda le restará visibilidad en un mundo en el que, en el año 2015, con más de 7.300 de dispositivos, el número de teléfonos móviles superó por primera vez el número de personas en el mundo (Ditrendia, 2015).

Queda demostrado, pues, que las narrativas transmedia pueden jugar un papel muy interesante a la hora de explicar contextos, historias y situaciones de la vida real. Sin embargo, las Organizaciones No Gubernamentales (ONG) se encuentran aún muy por detrás del desarrollo que ha realizado el periodismo. Al igual que ha sucedido con los medios de comunicación, estas organizaciones han experimentado para bien y para mal el cambio de paradigma comunicativo propiciado por Internet. La red ha democratizado el acceso a la información y ha acabado con la figura del gatekeeper, entendido como el individuo que actúa «en las empresas periodísticas seleccionando las informaciones que llegan a ellas acerca de los acontecimientos ocurridos, al considerarlas como más relevantes o de mayor interés para una determinada audiencia» (Armañanzas, 1993). También ha puesto fin a la teoría de la agenda-setting y ha fragmentado las audiencias de tal forma que es difícil llegar a un público masivo a través de un único medio. El desconcierto ha cundido entre los equipos de comunicación de las ONG, que son conscientes de que ya no es suficiente con conseguir que sus temas se incluyan en un medio de gran tirada para darse a conocer. Es necesario buscar otra forma de llegar a nuevas audiencias, ya que:

Son las mismas comunidades las que están generando el contenido a través de blogs, páginas independientes y redes sociales. Para audiencias fragmentadas, medios especializados. Ya no hay una única manera de 
llegar al consumidor, pues ya no hay un único consumidor, hay cientos (Gómez, 2011).

Se impone, pues, un modelo de comunicación basado en los contenidos. Una buena historia es el único hilo que a día de hoy puede guiar a diferentes públicos a través de un universo narrativo común. En el caso de las ONG este universo contribuirá a que puedan contextualizar su trabajo de forma adecuada para seguir recibiendo el apoyo económico que necesitan. Pero es necesario que sean muy cuidadosas a la hora de diseñar cada material para que funcione correctamente en el soporte elegido. Como dijo Henry Jenkins, en este tipo de narrativas «cada medio hace lo que mejor sabe hacer» (Jenkins, 2003).

En este contexto, las narrativas transmedia se abren ante las organizaciones sociales como un camino al que aventurarse por primera vez. Sin embargo, como si del viaje del héroe de Joseph Campbell se tratara, existen en el trayecto numerosas dificultades a las que enfrentarse antes de llegar al éxito. El tercer sector, conformado por las organizaciones que actúan dentro del sector no lucrativo como ONG, fundaciones, cooperativas, presenta una serie de dificultades comunicativas propias, como el reto de captar nuevas audiencias o el desconocimiento de los temas que trabajan por parte del público general. Asimismo, dentro de los departamentos de comunicación deberán actualizar su conocimiento sobre el nuevo entorno móvil, evitar la falta de planificación previa a la hora de desarrollar las extensiones transmedia, conseguir que se entienda el mensaje social detrás de cada extensión y alentar a los usuarios a que creen y compartan opiniones que hasta ahora consideraban reservadas para sus expertos y expertas. En resumen, nos encontramos al inicio de una revolución que cambiará el modelo comunicativo de las ONG y sobre todo su forma de entender la comunicación. Un punto de inflexión que recuerda sin duda a la pérdida de hegemonía y a la ruptura del mensaje unidireccional que vivieron los grandes medios de comunicación. ¿Estarán dispuestas a asumirlo?

\section{OBJETIVOS E HIPÓTESIS}

El objetivo principal de este artículo es analizar el proyecto Sí me importa de la organización española Oxfam Intermón, por considerar que se trata de un proyecto transmedia con fines sociales de larga duración que no posee precedentes en nuestro país. Como objetivo específico se señala el de conocer como Oxfam Intermón ha hecho uso de las narrativas transmedia para informar a la audiencia en general y a su base social, es decir, a las personas que tienen relación con la organización, de la importancia de la cooperación al desarrollo, la política pública más recortada desde el inicio de la crisis en 2008.

En esta aportación se plantea la hipótesis de que la fase de lanzamiento de la campaña Sí me importa, difundida bajo el nombre 3 de10, consiguió sus objetivos de difusión y sensibilización gracias a las narrativas transmedia llegando a nuevos públicos. Esta hipótesis permite plantear que los materiales se desarrollaron teniendo en cuenta el nuevo entorno móvil y se adaptaron al uso de los smartphones.

\section{ESTADO DE LA CUESTIÓN}

Desde el punto de vista académico, las narrativas transmedia han sido estudiadas en su mayor parte por su utilidad y aplicación en el mundo de la ficción. Abundan los estudios sobre series de televisión, como Battlestar Galáctica (Hernández y Grandío, 2011), Juego de Tronos (Lozano, Raya y López, 2013) o la serie española Águila Roja (Costa y Piñeiro, 2012, pp. 102-125). Asimismo, en nuestro país son frecuentes los trabajos que presentan estudios de caso sobre series de producción propia de 
las cadenas de televisión española, tanto privadas como públicas (de Lara y Arias, 2014; Villa, 2011; Rodríguez, 2013).

También el periodismo transmedia es hoy en día otra de las áreas más estudiadas, especialmente por el autor Denis Renó (Renó y Flores, 2012; Renó, 2012; Renó y Renó, 2013).

Asimismo, este tipo de narrativas son utilizadas en campañas de publicidad debido a la necesidad actual de reconvertir el discurso publicitario de las marcas, que mediante las narrativas transmedia «tienen la oportunidad de generar un espacio de cercanía con sus consumidores [...]. Si esas historias están tejidas con los mimbres de la narrativa transmedia podrán ser más intensas, más interactivas, más completas, más ubicuas... más envolventes» (Barral, 2013). Una de las campañas más conocidas es la campaña Destapa la felicidad de la marca Coca Cola (2009). Sin embargo, no es frecuente encontrar muchos estudios al respecto. Destacamos un estudio sobre las narrativas transmedia en las empresas de moda internacional (Villena, 2013) y otro sobre las estrategias narrativas en la publicidad audiovisual de Manos Unidas y Unicef (Marfil-Carmona, 2013). Este último trabajo se puede citar también como uno de los escasos ejemplos de análisis de caso sobre transmedia aplicado a causas sociales. No obstante, en el texto el autor de dicho trabajo admite haber encontrado dificultades para analizar las técnicas publicitarias de las organizaciones desde un punto de vista transmedia:

Los ejemplos descritos en este artículo establecen una plataforma óptima de interactividad, gracias a esa innovación, pero no llegan a generar desarrollos transmedia en toda su amplitud posible, ya que se echa de menos en estas experiencias el uso de otros soportes, como juegos (digitales y no digitales), blogs, producciones audiovisuales y mecanismos de creación más allá de la fotografía, plataformas de podcast, etc. (MarfilCarmona, 2013, p. 178).

En cuanto a los estudios sobre el tipo de comunicación que realizan hoy en día las ONG destacamos el trabajo de la Coordinadora de ONG para el Desarrollo-España con la publicación \#ParadigmáTIC@s. Comunicación y cultura digital en las ONG de Desarrollo (2012).

Entre los autores revisados destaco a Denis Renó, especializado en periodismo transmedia, quien mostró gran interés por el tema de este artículo: «Creo que es el camino para las narrativas transmedia: no más intentar definirla, sino descubrir qué hacer con ella, es decir, su aplicabilidad».

\section{MetodologíA}

Este artículo tiene su origen en la investigación Transmedia más allá de la ficción, cuyo interés se centraba en el análisis de las narrativas transmedia aplicadas a la difusión de contenidos de carácter social por parte de organizaciones no gubernamentales.

Se ha realizado un estudio de caso aplicado a la extensión 3 de10, correspondiente a la fase de lanzamiento del proyecto transmedia Sí me importa. Dicho estudio estaba destinado a comprobar la eficacia de las narrativas transmedia en un sector especializado en contar historias que promuevan la participación de la ciudadanía para lograr un cambio social: las organizaciones no gubernamentales. Para los autores Escudero, Delfín y Gutiérrez, la idoneidad del estudio para este tipo de investigación de caso se define de la siguiente manera:

La estrategia de investigación de estudio de caso es el método más adecuado cuando se plantea en el estudio una pregunta de investigación donde su forma es del tipo ‘¿cómo?' y ‘¿por qué?’, se tiene poco o nulo grado de control sobre el comportamiento real de los objetos/eventos 
en estudio y su temporalidad es contemporánea (Escudero, Delfín y Gutiérrez, 2008, p. 10).

Esta técnica de investigación permite conocer cómo se aplicaron las narrativas transmedia en la fase de lanzamiento de la campaña Sí me importa, cómo se organizaron y estructuraron (qué plataformas emplearon, qué contenidos difundieron en cada una de ellas y a qué públicos se dirigieron) y el éxito o fracaso de los resultados obtenidos en la fase de lanzamiento. Para ello, el estudio de caso incorpora, además de otras estrategias propias de la investigación, «dos fuentes de evidencia: la observación directa del o los eventos en estudio y la entrevista con individuos involucrados en dichos eventos» (Escudero, Delfín y Gutiérrez, 2008, p. 9).

Durante el lanzamiento de Sí me importa, entre el 12 y 30 de septiembre de 2014, se difundió la franquicia 3 de10, un falso reality show. Es decir, se simuló la emisión de un «programa de televisión que presenta a sujetos comunes y corrientes interactuando entre sí, exponiendo diferentes situaciones de su vida real siendo captados por cámaras» (Medina y Villarreal, 1998). Su difusión tuvo lugar principalmente a través de redes sociales, YouTube y web. En este caso de estudio concreto, la observación se basó en el visionado de los vídeos implicados en 3 de10, de la acción en redes sociales y de la implementación que se hizo en el nuevo entorno móvil. Respecto a la entrevista, se realizó con Saya Sauliere, coordinadora de proyectos digitales y monitoreo de la campaña Sí me importa, el día 24 de abril de 2015. Asimismo, la autora pudo sumar a la experiencia personal aportada por Sauliere la suya propia, ya que formó parte del equipo de comunicación de Oxfam Intermón durante el periodo de estudio establecido.

Para establecer las conclusiones del estudio de caso se trabajó sobre los resultados obtenidos por Oxfam Intermón durante la difusión de 3de10:

Twitter: se trabajó sobre un total de 2.672 perfiles que usaron la etiqueta propuesta y hablaron del tema y sobre un total de 1.062 seguidores, obtenidos en el total de las tres fases del proyecto 3 de 10 .

YouTube: el estudio se realizó sobre las visualizaciones totales de los tres vídeos de la campaña, separándolas en visualizaciones orgánicas, a las que se ha accedido por medios no promocionales, como el vídeo compartido por otra persona o a través de búsquedas, que fueron un total de 37.300; y las publicitarias que fueron 24.371.

La página web de la campaña: en este caso se tuvieron en cuenta el número de visitas a la web, un total de 9.341 visitas únicas, y el número de firmas obtenidas, que fue de 1.996.

En una segunda fase se analizó el uso del smartphone o cuarta pantalla, con el objeto de conocer si se había utilizado su capacidad en esta campaña.

Tras esta recogida de datos a partir de la aportación de Oxfam Intermón se procedió al análisis de los mismos para conocer el nivel de participación de los usuarios en las distintas fases de la campaña 3 de10. Posteriormente, la puesta en relación de los datos de participación con los objetivos de la campaña 3 de10 permitió conocer el nivel de efectividad de la utilización de narrativas transmedia en un área en la que todavía no han sido muy difundidas.

\section{LA COMUNICACIÓN EN LAS ORGANIZACIONES NO GUBERNAMENTALES}

«Cómo labrarse un prestigio social si los destinatarios de tu mensaje no quieren prestarte atención en el lenguaje en que les hablas?» (Barral, 2013). Ese es el gran reto. Las grandes campañas de marketing de las ONG que buscaban un impacto masivo, como la cartelería en marquesinas de autobús o los anuncios en televisión, han quedado desfasadas a la hora de buscar nuevas audiencias. Ya no existe una fórmula mágica que sirva para todo el mundo. Internet permite que las empresas y organi- 
zaciones sean más selectivas, impactando a audiencias seleccionadas con productos específicos diseñados para explotar al máximo las características de cada soporte.

Según datos del Instituto Nacional de Estadística (INE) del 2015, el 64,3\% de la población de 16 a 74 años utiliza internet a diario. Atendiendo de forma más específica al fenómeno de los smartphones, en 2015 el 96,7\% de los hogares disponía de al menos un teléfono móvil. Además, entre los menores la disposición de teléfono móvil se ha incrementado significativamente a partir de los 10 años hasta alcanzar el 90,9\% en la población de 15 años en 2015.

La importancia del móvil es tal que empiezan a surgir estrategias que sitúan al smartphone como el primer soporte que se debe tener en cuenta en el diseño de una estrategia comunicativa:

En la nueva ecología de medios, [...] hay quienes se han decidido a pensar sus proyectos desde una mirada mobile first, esto es: pensando prioritariamente en audiencias móviles. Es claro que, si se piensa primero en la movilidad, los procesos de trabajo cambian, al igual que la producción creativa y el desarrollo del contenido (Lovato, 2015).

Pensando en esta lógica de cuarta pantalla, ya han surgido los primeros productos que adaptan formatos más antiguos, como el vídeo en YouTube, al nuevo entorno móvil. Un ejemplo muy interesante con un mensaje social de fondo es el caso de BBC Media Action, que en julio de 2016 lanzó su primer vídeo vertical para consumir en el móvil con el objetivo de situar al usuario en la piel de un refugiado que intenta cruzar el Mediterráneo. La organización entrevistó a 79 refugiados y 45 trabajadores de ONG para producir esta pieza inmersiva. Cuenta con 233.332 visualizaciones a fecha de septiembre de 2016.

Figura 1. Imagen del vídeo de BBC Media Action

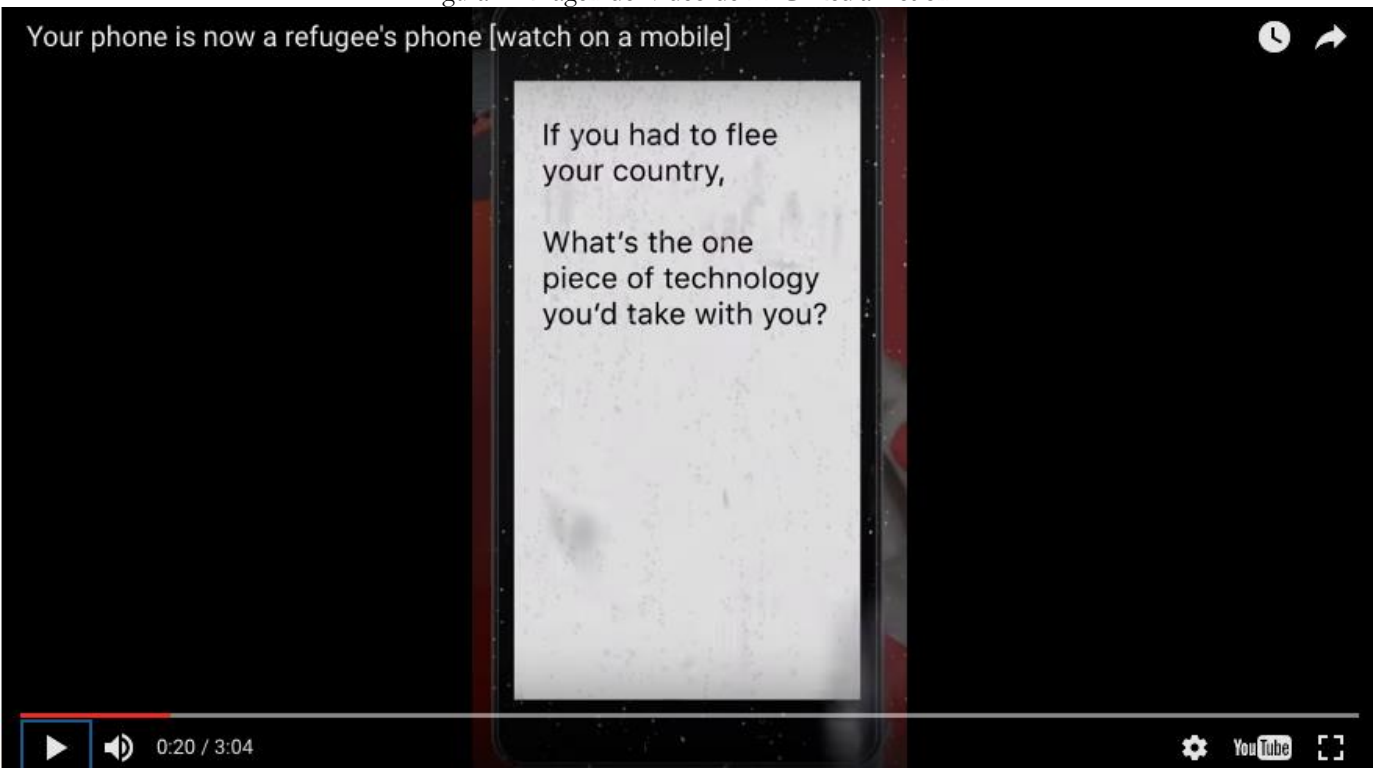

Fuente: YouTube. 
Las ONG también deben adaptarse a este cambio de paradigma, que ha afectado ya de forma directa a su forma de trabajar, como explica Lucila Rodríguez-Alarcón, exdirectora de comunicación de Oxfam Intermón:

El rol de las organizaciones no gubernamentales ha ido cambiando con el tiempo. En sus orígenes a principios del siglo pasado, la mayoría de las organizaciones eran eminentemente asistencialistas. [...] Con el tiempo, algunas organizaciones empezaron ir más allá; «no les des pescado, dales una caña y enséñales a usarla». Pero muchas no se detuvieron ahí sino que llevaron la reflexión un paso más adelante. Empezaron a trabajar con las personas que lo necesitan en la identificación de las causas de su situación promoviendo que sean ellas mismas las que elijan cómo quieren solucionar el problema (Rodríguez-Alarcón, 2014).

Hasta finales del siglo XX, las organizaciones sociales habían comprendido la comunicación como una mera transmisión de información o como un sistema de persuasión de conductas. Así lo explica Victor Marí Sáez, experto en comunicación educativa:

El primer modelo -la comunicación como transmisión de informaciónsuele llevar a la búsqueda de un impacto en medios por parte de la ONG. El segundo modelo -la comunicación como persuasión de conductaslleva en numerosas ocasiones a aplicar en la comunicación solidaria unas estrategias de comunicación y de marketing que son una traslación literal de las estrategias que se implementan en el ámbito empresarial. Desde esta lógica, la comunicación se orienta principalmente a vender la organización a la sociedad (Marí, 2012).

Ambas corrientes dejaban de lado la comunicación para el cambio social, que «pone el acento en la importancia de dinamizar procesos sociales de transformación, en los que el ciudadano/a no se siente únicamente apelado a realizar aportaciones económicas, sino que participa activamente, junto a otras personas, en generar cambios sociales» (Marí, 2012). Por el contrario, se centraban en lo que Javier Erro, investigador de comunicación y educación para el desarrollo, denomina comunicación mercadeada: «sometimiento de la comunicación, por parte de las ONG, a fines instrumentales [...], como un instrumento orientado a la captación de recursos financieros y/o humanos para la entidad solidaria» (Marí, 2012).

Hoy en día predomina un modelo mixto, que combina la comunicación para el cambio social con la necesidad de conseguir fondos para el mantenimiento de la organización y su labor. Muchas organizaciones han terminado configurándose como activistas de derechos humanos, contra la pobreza, la desigualdad o el cambio climático; y tratan de cambiar las leyes y decisiones políticas para que sean lo más justas posibles. Para ello necesitan el apoyo de la ciudadanía que canalizan, principalmente, a través de peticiones de firmas. Numerosos son los ejemplos de peticiones para apoyar causas como la protección del medioambiente, la defensa de los derechos de las personas refugiadas o la reforma del sistema fiscal internacional, entre otros. 
Figura 2. Petición de la organización Save The Children en Facebook

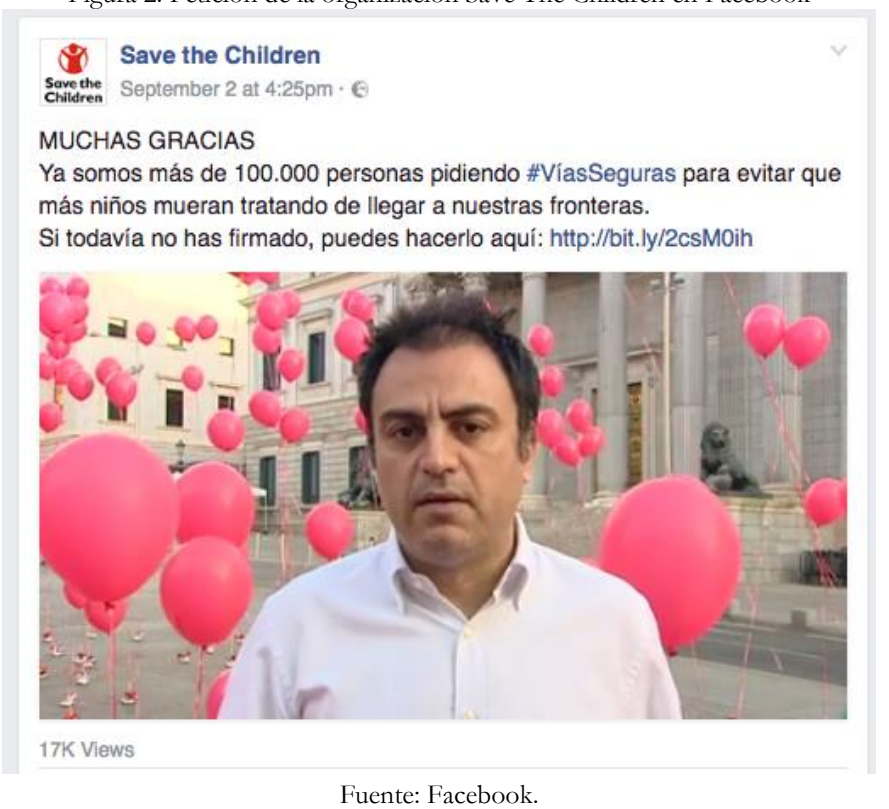

No obstante, detrás de cada firma sigue estando presente un objetivo de captación de leads o registros de usuarios con nombre, apellido, email y/o teléfono a través de un formulario en la web. Gracias a estos registros la organización podrá contactar con la persona que ha firmado la petición y ofrecerle nuevas peticiones para firmar, más información sobre el trabajo de la ONG y finalmente la opción de convertirse en socio o socia. Esa conversión será, en muchos casos, la que medirá finalmente el éxito de la acción. Vemos, pues, que la comunicación mercadeada comentada anteriormente no ha desaparecido, sino que se combina con la comunicación para el cambio social y se camufla para que la audiencia no la perciba directamente.

Para lograr sus objetivos las organizaciones no dudan en diseñar vídeos para redes sociales, aportar datos complementarios para que su audiencia pueda sentirse bien informada, publicar entrevistas... Sin embargo, cabe preguntarse si realmente sacan el máximo partido a cada soporte o si se están limitando a reproducir los mismos materiales en diferentes medios.

\section{LAS NARRATIVAS TRANSMEDIA COMO CLAVE PARA AMPLIAR INFORMACIÓN}

En un panorama en el que las comunidades afectadas por un problema pueden expresar sus demandas y pedir a la ciudadanía internacional el apoyo que necesitan directamente a través de Internet, ¿a qué papel han quedado relegadas las grandes organizaciones? Sin duda, salvo en los casos de emergencias humanitarias, empiezan a ser sometidas a un rol de intermediarias, como entidades que aportan su expertise o saber hacer a las comunidades y organizaciones locales con las que trabajan, dotan de credibilidad a sus demandas y aportan los fondos económicos y la infraestructura necesarios.

De cara a los posibles socios y socias o donantes, para las organizaciones resulta vital explicar y contextualizar correctamente las causas que defienden y presentarse como expertas e impulsoras de un cambio necesario. Es su valor añadido en un momento en el que «gracias a las nuevas herramientas comunicativas los ciudadanos se sienten capaces de cambiar por sí mismos lo que estiman que debe cambiar» (Rodríguez-Alarcón, 2014). Actualmente, la ciudadanía puede ejercer directamente la presión 
necesaria sobre los gobiernos y autoridades para lograr cambios sociales, a través de plataformas como Change.org o Avaaz y realizar sus propias peticiones. Por tanto, es necesario poder ofrecer algo más: una buena historia.

Como es sabido, la base de una buena narrativa transmedia es su historia. Las organizaciones cuentan con interesantes relatos procedentes de contextos y países muy diferentes. Esta riqueza les brinda la oportunidad de expandirlos de forma óptima a través de diferentes soportes. Así lo explica la agencia de publicidad Materia Gris, especializada en proyectos de ONG y fundaciones; en el blog de su página web podemos leer:

\begin{abstract}
Detrás de cada una de estas organizaciones hay siempre una historia apasionante que contar. [...] Situar a esas historias en el centro de las estrategias de comunicación de este tipo de organizaciones es hoy la clave para provocar los cambios que ellas propugnan y que tanto necesita nuestra sociedad (Materia Gris, 2014).
\end{abstract}

Por tanto, las organizaciones pueden valerse de las características propias de las narrativas transmedia para ampliar información sobre sus programas y acercarse a la participación activa de sus seguidores. Además, gracias a su prestigio, muchas personas preferirán participar en las campañas transmedia propuestas por ellas antes que unirse a otras de menor reconocimiento. Se trata de una oportunidad, pero también de un territorio desconocido para muchas organizaciones.

\title{
7. CAMPAÑA SÍ ME IMPORTA DE OXFAM INTERMÓN
}

Oxfam Intermón es una organización española no gubernamental de cooperación para el desarrollo que centra sus actividades en ofrecer una respuesta integral al reto de la pobreza y la injusticia. Estructuralmente, como otras muchas organizaciones, Oxfam Intermón se divide en diferentes departamentos, como el departamento de comunicación, de personas y organización o el de campañas y ciudadanía, entre otros. Este último departamento englobaba la unidad Más y Mejor Ayuda (MyMa), responsable de la creación y desarrollo de la campaña transmedia Sí me importa, dentro del cual se desarrolló el falso reality show 3 de10 que se analizará a continuación. Esta unidad se caracterizó por llevar a cabo proyectos innovadores. Se trató de un equipo joven, cuya filosofía de trabajo fue innovar y aprender. Eran conscientes, como explicaba Saya Sauliere, coordinadora de proyectos digitales y monitoreo de la campaña Sí me importa, de que en el paradigma actual «hay que ser mucho más atractivos y estratégicos, con mucha más capacidad de entender el funcionamiento de las audiencias y de hablar un lenguaje diferente que sintoniza con sus pensamientos»².

La campaña Sí me importa fue concebida desde su inicio como un proyecto transmedia, lo que la convirtió en una campaña innovadora y diferente a las campañas que realizan tradicionalmente las ONG. Su temática principal, la importancia de la ayuda oficial al desarrollo, es un tema duro desde el punto de vista comunicativo y de escaso interés fuera de audiencias muy específicas, ya fidelizadas y familiarizadas con el sector. En el siguiente extracto, Saya Sauliere explica por qué consideraron que las narrativas transmedia podían ser de utilidad a la hora de comunicar dicho tema:

El problema de las ONG es que están ofreciendo una comunicación que tiende a ser muy endogámica. No deberíamos sensibilizar a gente ya sen-

2 Entrevista realizada por la autora el 24 de abril de 2015. 
sibilizada. Así que lo que pensamos es que si se usan diferentes lenguajes que ya tienen su audiencia, el mensaje va a llegar por naturaleza a diferentes audiencias ${ }^{3}$.

Llegar a nuevas audiencias era uno de los principales objetivos del proyecto. Asimismo, se pretendía generar una corriente ciudadana que reivindicara la importancia de la cooperación al desarrollo a través de la firma de una petición. Para ello se plantearon varias vías de comunicación, que constituyeron cada uno de los subproyectos y extensiones transmedia de la campaña. Los soportes utilizados fueron los siguientes:

Tabla 1. Extensiones transmedia de la campaña Sí me importa de Oxfam Intermón.

\begin{tabular}{|l|l|l|l|}
\hline Soporte & Proyecto & Web propia & Descripción \\
\hline Cómic & $\begin{array}{l}\text { Viñetas de } \\
\text { vida }\end{array}$ & ojoylapiz.com & $\begin{array}{l}\text { Ocho dibujantes españoles de cómic viajan a países de África, América } \\
\text { Latina y Asia para conocer diferentes proyectos con apoyo de las ayudas } \\
\text { a la cooperación y plasman su experiencia en diferentes cómics, disponi- } \\
\text { bles a través de la web y de aplicaciones para Android y iPhone, y en } \\
\text { papel. }\end{array}$ \\
\hline Arte & $\begin{array}{l}\text { cuestionAR- } \\
\text { TE }\end{array}$ & - & $\begin{array}{l}\text { Siete artistas españoles viajan a Latinoamérica, África y Asia para conocer } \\
\text { distintos proyectos de desarrollo con apoyo de las ayudas a la coopera- } \\
\text { ción. Las obras plásticas resultantes se expusieron públicamente en } \\
\text { diferentes espacios, como el Colegio Oficial de Arquitectos de Madrid o } \\
\text { la Casa de las Conchas de Salamanca. }\end{array}$ \\
\hline Cine & actuARTE & $\begin{array}{l}\text { laciamy- } \\
\text { ma.com }\end{array}$ & $\begin{array}{l}\text { Bajo el nombre de La Compaña Myma, la organización representa a través } \\
\text { del teatro diferentes situaciones relacionadas con la ayuda a la coopera- } \\
\text { ción en espacios como la Universidad Autónoma de Madrid o las plazas } \\
\text { y calles del Barrio de las Letras de Madrid, entre otros. }\end{array}$ \\
\hline $\begin{array}{l}\text { 9 días en Haití es un cortometraje documental narrado en primera persona } \\
\text { por el director J. A. Bayona. La escuela del campo de desplazados de } \\
\text { Corail-Cesselesse en Puerto Príncipe es el escenario principal. Se trata de } \\
\text { un proyecto que lucha por sobrevivir cada año para poder seguir dando } \\
\text { educación y alimentación básica a 400 niños y niñas desplazados tras el } \\
\text { terremoto de 2010. }\end{array}$ \\
\hline
\end{tabular}

Fuente: elaboración propia a partir de datos de Oxfam Intermón.

Como se puede apreciar cada extensión cuenta con un nombre de proyecto propio y, en algunos casos, un espacio web independiente de la web principal de la campaña Sí me importa. Asimismo, cada una de ellas fomenta la participación de la audiencia de diferente forma. Por ejemplo, mediante la difusión en redes sociales y espacios de encuentro con los dibujantes en el caso del cómic o la posibilidad de crear una obra de teatro con la temática de cooperación en el caso del teatro, entre otras.

Los creadores de la campaña tuvieron en cuenta la necesidad de adaptar sus productos a la nueva realidad móvil. Así, la web principal y las webs de los subproyectos son responsive. En ellas aparecen botones que permiten seguir los perfiles de Twitter y Facebook y compartir en ellos la información de forma rápida y directa desde el dispositivo móvil. Además, los vídeos de promoción del corto documental o las entrevistas relacionadas se subieron a YouTube, lo que permite una visualización cómoda para los usuarios móviles. Por otro lado, en el caso de la extensión cómic se desarrolló una aplicación gratuita para web y otra para Android e iOS bajo el nombre de Cómic On Tour. Dicha app contenía las

3 Entrevista realizada por la autora el 24 de abril de 2015. 
mismas historias que el cómic en papel y fue galardonada con Laus Plata 2015, organizados por la Asociación privada sin ánimo de lucro de Diseñadores Gráficos y Directores de Arte de España.

Sin embargo, «las NT no son simplemente una adaptación de un lenguaje a otro: la historia que cuenta el cómic no es la misma que aparece en la pantalla del cine o en la microsuperficie del dispositivo móvil» (Scolari, 2013, p. 29). Por tanto, desde el punto de vista transmedia, podría haber sido más interesante desarrollar una aplicación que permitiera visitar a través de realidad virtual los proyectos que aparecen en el cómic y/o subir contenido alternativo a los prosumidores, por poner algunos ejemplos.

\subsection{ESTUDIO DE CASO: 3DE10, EL REALITY DE LA COOPERACIÓN}

El lanzamiento oficial de la campaña Sí me importa tuvo lugar en septiembre de 2014 a través del falso reality show 3de10. El periodo de análisis comprende del 12 al 30 de septiembre de 2014.

3 de10 es un proyecto totalmente independiente del resto de extensiones transmedia de la campaña Sí me importa (cómic, teatro, arte y cine). Debe su nombre al número de participantes del reality que podían salvarse gracias a la votación de la ciudadanía. Basándose en que la Ayuda Oficial al Desarrollo es una de las políticas públicas españolas más recortadas desde el inicio de la crisis (un $70 \%$ desde el año 2008) y a través del formato de reality elegido se pretendía expresar de forma simplista y alegórica la situación actual de la cooperación: con los recortes, donde antes se podía beneficiar a diez personas, ahora solo se puede llegar a tres. Por lo tanto, los votantes del reality 3 de10 tenían que descartar a esas siete personas que no merecían seguir recibiendo la ayuda española.

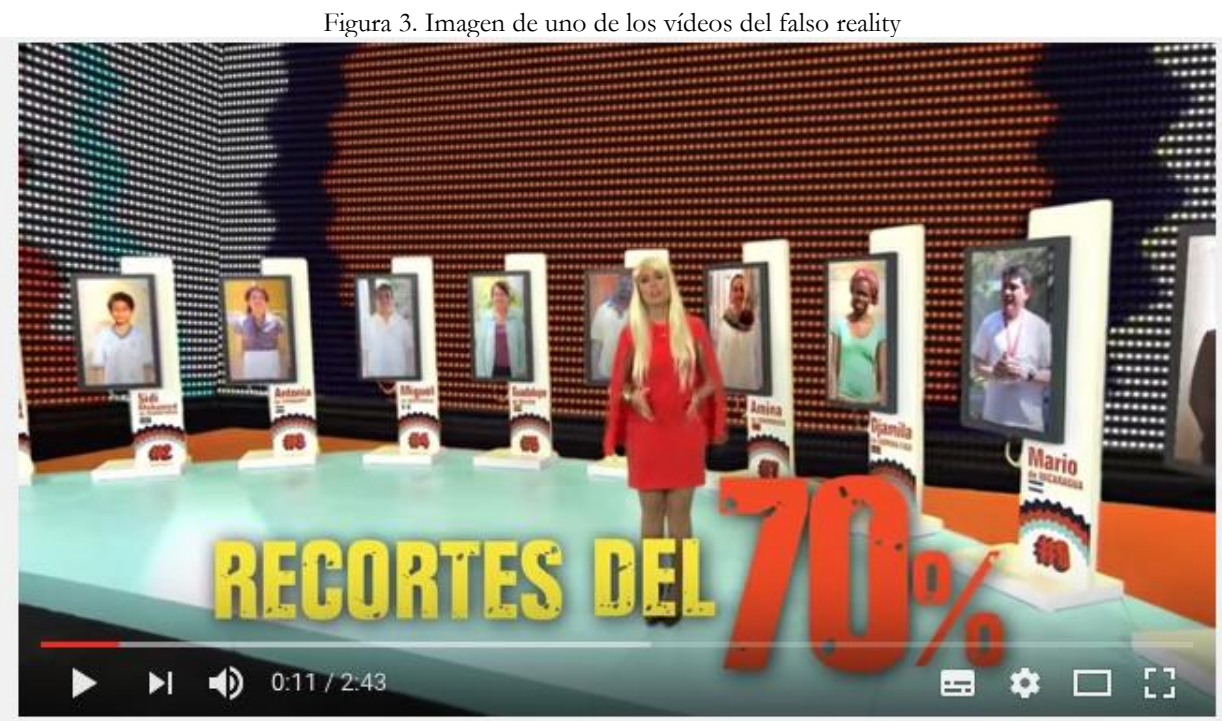

Fuente: YouTube.

Hasta el 23 de septiembre de 2014, 3 de10 permaneció sin marca asociada, es decir, no se reveló que era Oxfam Intermón quien estaba detrás del supuesto programa televisivo. Además, la difusión se apoyó en la colaboración con personalidades del mundo de la comunicación para conseguir obtener mayor interés y relevancia. Algunas de estas fueron las periodistas Rosa Montero, Julia Otero o Marta Nebot, los actores Marta Larralde, Alberto Jiménez o Álex Gadea o el youtuber El Rubius. 


\subsection{DesarRollo TRANSMEDia DE 3DE10}

Desde el punto de vista transmedia, el lanzamiento constó, en rasgos generales, de tres vídeos principales y otros diez videos secundarios con testimonios de actores, que simulaban ser los concursante del programa; perfiles oficiales en Twitter, Facebook y YouTube; una web de votación en la que participar en tiempo real y de forma directa en el concurso; y, a partir del 23 de septiembre, fecha del lanzamiento de la campaña Sí me importa, difusión en medios de comunicación, una nueva web y perfiles en redes sociales, que se corresponden actualmente con la web y perfiles oficiales de dicha campaña. En conjunto, a través de un lenguaje transgresor, sarcástico y disruptivo todas las plataformas contribuyeron a construir un universo narrativo alrededor de la temática de cooperación con el fin de que la ciudadanía pudiera entender de una forma diferente, alternativa y participativa qué suponen los recortes en cooperación para la vida de miles de personas.

Cabe destacar que 3 de10 imitó una forma de entrada a la experiencia transmedia propia de los Juegos de Realidad Alternativa, que suelen «comenzar con un enigma que resolver presentado en la web o en un clip televisivo (esta puerta de ingreso se llama rabbithole o trailhead) y continuar en cualquier tipo de medio de comunicación, plataforma de contenidos o espacio físico» (Scolari, 2013, p. 462). Así, 3 de10 pretendió generar interés en la audiencia a través de un teaser de 51 segundos de duración en el que reconocidas personalidades del mundo de la comunicación expresaban su desconcierto e indignación ante la supuesta producción de reality show que jugaba con la vida de las personas. Este primer vídeo no explicaba en detalle en qué consistía el programa ni por qué podía ser tan polémico. Era, por tanto, un auténtico enigma que pretendía mantener la expectación de la audiencia hasta el próximo vídeo, que se correspondía con el estreno oficial del supuesto reality, el día 16 de septiembre de 2014. Para mantener el interés, durante los días de espera se publicaron constantemente mensajes en Twitter y Facebook de carácter irónico y político sobre los recortes en cooperación.

\subsection{FASES Y OBJETIVOS DE 3DE10}

A continuación, se explican de forma esquemática las diferentes fases que se desarrollaron durante el lanzamiento y los objetivos de cada una de ellas, gracias a los datos facilitados para este artículo por la unidad Más y Mejor Ayuda de Oxfam Intermón:

1. Fase de cebo (12-15 de septiembre): lanzamiento del teaser y de los perfiles 3 de10 en Twitter, Facebook y You'Tube.

- Objetivos

- Crear expectativa respecto al reality 3 de10.

- Lograr visualizaciones del primer vídeo (teaser) en YouTube.

2. Fase reality (16 al 22 de septiembre): lanzamiento del segundo vídeo y de la web 3 de10 en la que se podían realizar las votaciones para descartar a los participantes del reality.

- Objetivos

- Informar sobre los recortes del $70 \%$ y despertar interés y polémica alrededor del reality.

- Generar seguidores y fans de los perfiles de Twitter y Facebook.

- Generar tráfico en la web de 3 de10.

- Generar visualizaciones del segundo vídeo, que explicaba la dinámica del concurso, presentaba a los participantes y animaba a la votación en la web. 
3. Fase Sí me importa (23 al 30 de septiembre): lanzamiento del tercer vídeo (vídeo de cierre) y perfiles oficiales de Sí me importa en redes sociales y web.

- Objetivos

- Generar movimiento Si me importa y leads adheridos al mismo, mediante la firma en la web con registro de datos personales, concretamente nombre, apellidos y email. El interés de los leads reside en la posibilidad que brindan a la organización de perpetuar el contacto y continuar enviándoles información relacionada con la campaña.

- Generar seguidores en las redes sociales de Si me importa.

- Generar tráfico en la web de Síme importa.

- Generar visualizaciones del vídeo de cierre, que incluía el mensaje principal de la campaña Sí me importa y desvelaba la marca Oxfam Intermón detrás del falso reality.

- Generar adhesión al movimiento Sí me importa a través de la difusión en medios de comunicación.

\subsection{Resultados DE 3 DE10}

Para entender correctamente los fenómenos que tuvieron lugar a lo largo de la ejecución del proyecto se debe tener en cuenta que 3 de10 estaba diseñado en base a una lógica lineal de compromiso del usuario o engagement. Por tanto, como toda estrategia de este tipo presentaba una serie de etapas de experiencia para las audiencias, que se desarrollan tradicionalmente en seis escalones según el modelo teórico de Forrester: desde el escalón cero de inactividad hasta el último escalón de creación propia y prosumición. En el caso de 3 de10, se pretendía que la audiencia pasara de ser inactiva a espectadora (primer escalón) mediante la visualización del primer vídeo sobre el reality (teaser) y la conversación generada en redes sociales. A partir de ahí era de esperar que fuera subiendo escalones hasta llegar, al menos, a la etapa participativa en las dinámicas propuestas (cuarto escalón), donde se convertiría en leads mediante la firma de la petición y unión al movimiento Sí me importa. Además, esta lógica lineal de engagement estaba diseñada en forma de embudo de conversión, que marca «la sucesión de pasos que un usuario debe ejecutar en un sitio web para realizar el objetivo principal que persigue el inicio del proceso» (Tayar, 2011).

A continuación se exponen los resultados generales del proyecto en base a los datos facilitados por la unidad Más y Mejor Ayuda de Oxfam Intermón:

\section{Comportamiento del proyecto en Twitter:}

Cabe destacar que Facebook no permite una monitorización correcta debido a su política de privacidad. En Twitter, frente a la lógica lineal planificada se produjo un fenómeno muy interesante: los perfiles que participaron en cada fase fueron diferentes. Es decir, se rompió la linealidad del engagement. Así, solo 109 perfiles participaron con la etiqueta \#3de10 antes y después del 23 de septiembre. Y solo 49 participaron con las dos etiquetas propuestas: \#3de10 (antes del 23 de septiembre) y \#meimporta (después del 23 de septiembre). En el resto de los casos cada fase generó su propia audiencia. 
Figura 4. Ruptura de la lógica lineal y del embudo de conversión en las redes sociales de 3de10

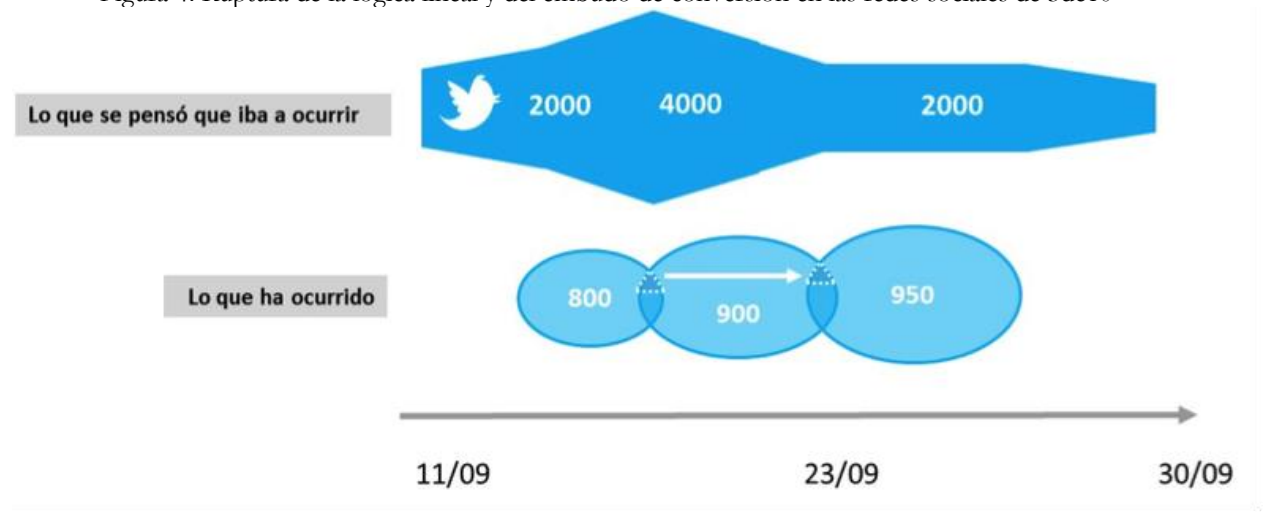

Fuente: Oxfam Intermón.

Aun así, durante todas las fases los resultados de seguidores y de conversación con las etiquetas se mantuvieron en un nivel alto o medio respecto a los indicadores definidos previamente.

Tabla 2. Seguidores y conversación en Twitter por fases

\begin{tabular}{|c|c|c|c|c|c|}
\hline \multirow[t]{2}{*}{ Fase } & \multirow[t]{2}{*}{ Indicador } & \multicolumn{3}{|c|}{$\begin{array}{c}\text { Indicadores prospecti- } \\
\text { vos }\end{array}$} & \multirow[t]{2}{*}{ Cumplimiento del objetivo } \\
\hline & & Alto & Medio & Bajo & \\
\hline \multirow[t]{2}{*}{ Cebo } & Seguidores@3de10 & 500 & 200 & 50 & Medio-alto: 400 seguidores \\
\hline & $\begin{array}{l}\text { Perfiles que hablan del } \\
\text { tema }\end{array}$ & 600 & 250 & 60 & Alto: 822 perfiles \\
\hline \multirow[t]{2}{*}{ Reality } & Seguidores@3de10 & 600 & 200 & 50 & $\begin{array}{c}\text { Medio-bajo: } 179 \text { seguidores } \\
\text { nuevos }\end{array}$ \\
\hline & $\begin{array}{l}\text { Perfiles que hablan del } \\
\text { tema }\end{array}$ & 1200 & 500 & 120 & Medio-alto: 900 perfiles \\
\hline \multirow[t]{2}{*}{ Sí me importa } & $\begin{array}{c}\text { Seguidores } \\
\text { @simeimportaORG }\end{array}$ & 1000 & 500 & 200 & Medio-bajo: 483 seguidores \\
\hline & $\begin{array}{c}\text { Perfiles que hablan del } \\
\text { tema }\end{array}$ & 2000 & 600 & 100 & Medio-alto: 950 perfiles \\
\hline
\end{tabular}

Fuente: elaboración propia a partir de datos de Oxfam Intermón.

En cuanto a las características de los perfiles que participaron en Twitter, a través de un análisis de las biografías se demostró que no se trataba de nuevas audiencias, sino de públicos relacionados con el sector, ya que las principales palabras que los usuarios utilizaban para describirse a sí mismos eran, entre otras, «periodista», «desarrollo», «cooperación», «social»y «comunicación». 
Figura 5. Tagcloud de la biografía de los perfiles que participaron con el hashtag \#3de10 antes del 23 de septiembre

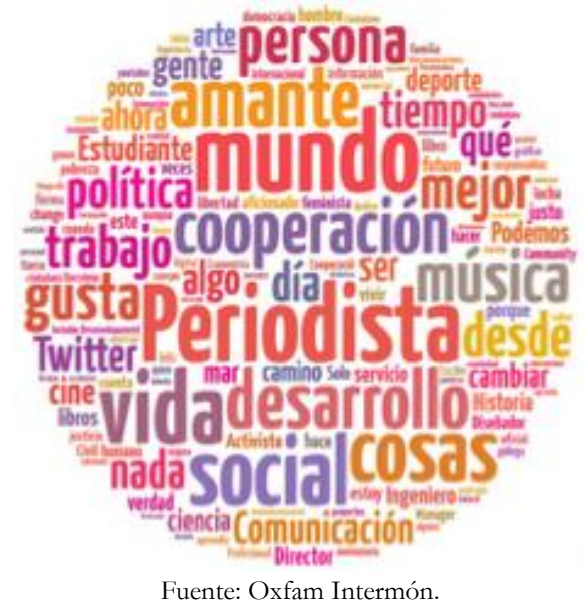

Figura 6. Tagcloud de la biografía de los perfiles que participaron con el hashtag \#meimporta después del 23 de septiembre

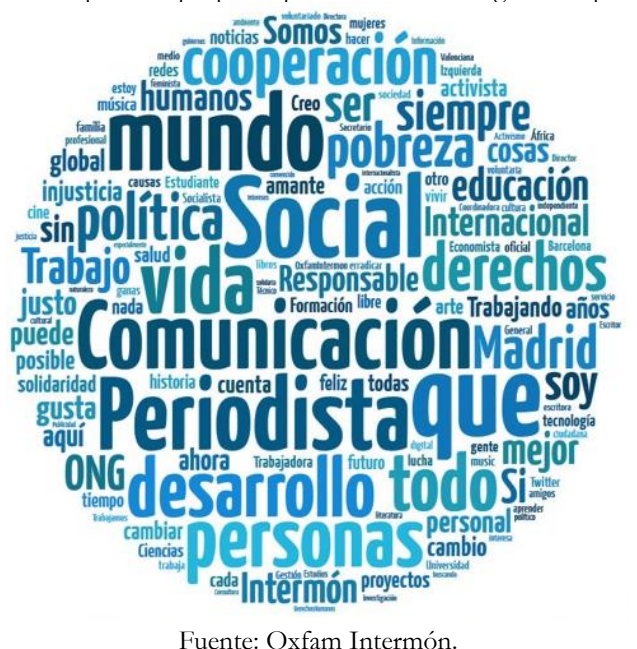

2. Comportamiento del proyecto en YouTube:

En YouTube, las visualizaciones habían sido planteadas siguiendo una lógica lineal. Estaba previsto que con cada nuevo vídeo aumentara el número de visualizaciones. Sin embargo, se experimentó un decrecimiento considerable en la visualización de los vídeos hasta llegar al vídeo de cierre. Además, al igual que había sucedido en Twitter, cada vídeo generó una audiencia propia. El último vídeo, que se consideraba el más importante al incluir el mensaje principal de la campaña, solo tuvo 5.300 visualizaciones orgánicas, es decir, visualizaciones que se realizan por una vía de entrada diferente a la publicitaria. Por ejemplo, a través de búsqueda en Google o YouTube, o de un enlace desde otra web o redes sociales. A ellas se pueden añadir unas 30.000 visualizaciones publicitarias. De todas ellas, 8.000 visualizaciones (5.000 visualizaciones orgánicas +3.000 visualizaciones publicitarias) llegaron hasta al final del vídeo en el que aparecía el mensaje principal de la campaña. 


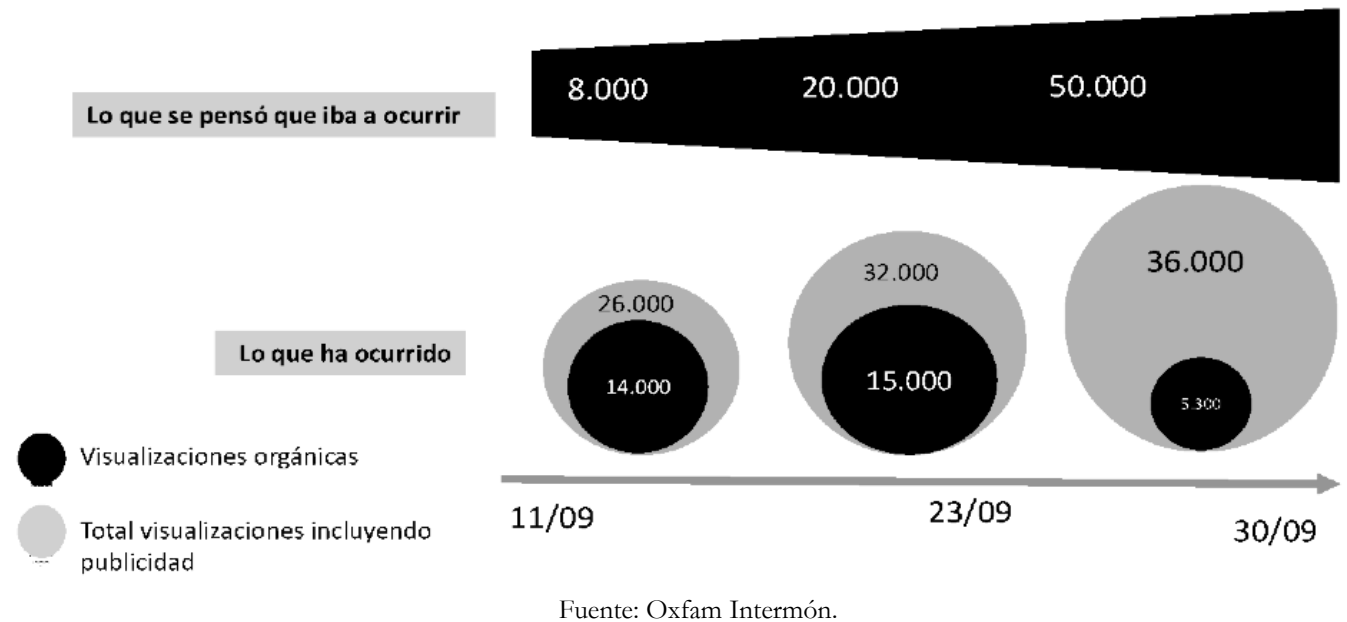

Aun así, nuevamente, se cumplieron las expectativas respecto a los indicadores definidos previamente para las visualizaciones orgánicas:

Tabla 3. Visualizaciones totales de los tres vídeos de 3 de 10

\begin{tabular}{|c|c|c|c|c|c|}
\hline Vídeo & Indicador & \multicolumn{2}{|c|}{$\begin{array}{c}\text { Indicadores prospectivos } \\
\text { (visualizaciones orgánicas) }\end{array}$} & $\begin{array}{c}\text { Cumplimiento del } \\
\text { objetivo }\end{array}$ \\
\cline { 3 - 5 } & & Alto & Medio & Bajo & \\
\hline $\begin{array}{c}\text { Teaser (00: } \\
\text { 51) }\end{array}$ & $\begin{array}{c}\text { Visualizaciones } \\
\text { totales }\end{array}$ & 8.000 & 5.000 & 1.000 & $\begin{array}{c}\text { Alto } \\
\text { TOTAL: } 25.786 \\
\text { Orgánicas: } 14.000 \\
\text { Publicidad: } 11.786\end{array}$ \\
\hline Reality (02: & $\begin{array}{c}\text { Visualizaciones } \\
\text { totales }\end{array}$ & 20.000 & 10.000 & 3.000 & $\begin{array}{c}\text { Medio-alto } \\
\text { TOTAL: } 27.955 \\
\text { Orgánicas: } 18.000 \\
\text { Publicidad: } 9.585\end{array}$ \\
\hline Cierre (01:34) & $\begin{array}{c}\text { Visualizaciones } \\
\text { totales hasta } \\
\text { mensaje final }\end{array}$ & 50.000 & 8.000 & 1.000 & $\begin{array}{c}\text { Medio-bajo } \\
\text { TOTAL: } 8.000 \\
\text { Orgánicas: } 5.300 \\
\text { Publicidad: } 3.000\end{array}$ \\
\hline
\end{tabular}

3. Comportamiento en cuanto a visitas a la web y conversión en leads:

Cabe recordar que el objetivo final de 3 de10 era sumar seguidores al movimiento Sí me importa que defiende la cooperación. Para ello, se habilitaba un formulario en la web Síme importa (a partir del 23 de septiembre) al que se podía llegar a través de diferentes canales (para este artículo se consideran los principales Facebook, Twitter, YouTube y las webs 3 de10 y Si me importa) y en el que los usuarios podían facilitar sus datos, convirtiéndose en leads. Entre los canales, el más efectivo para la conversión fue Facebook. El 36\% de los internautas que entraron en la web por Facebook apoyaron la campaña. En cambio, Twitter tuvo una ratio más baja de conversión, $8 \%$. YouTube tuvo una tasa del 28\%. Y la web 3 de10 y Si me importa tuvieron por su parte una tasa de conversión del 18\% y 22\%, respectivamen- 
te. A continuación, se pueden ver todos los canales de difusión ${ }^{4}$ que participaron en el proceso y su tasa de conversión (los datos mostrados corresponden al periodo del 23 de septiembre al 05 de octubre de 2014):

Figura 8. Número de visitas a la web SMI, número de firmas de apoyo a la campaña SMI, y tasa de conversión en base a los canales de difusión (ordenado por tasa de conversión)

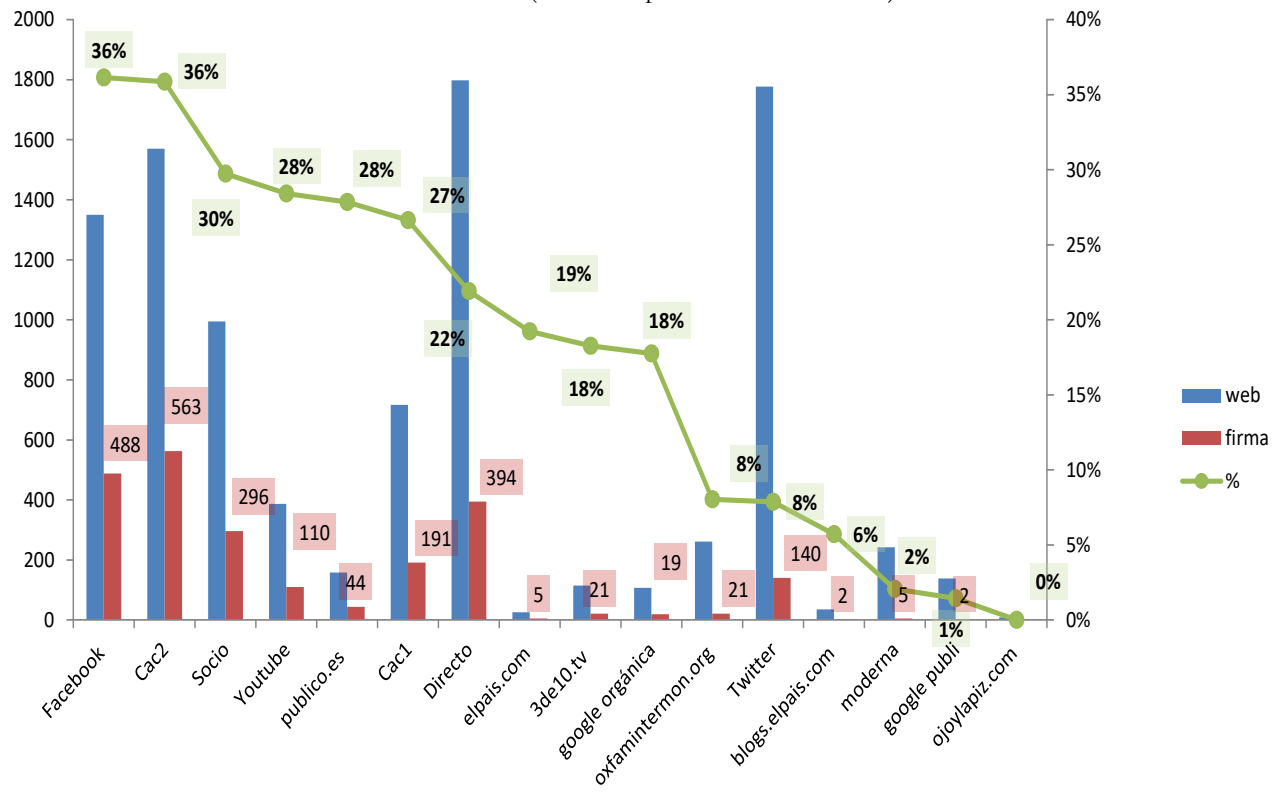

Fuente: Oxfam Intermón.

En resumen, en total en el periodo de estudio marcado (12-30 septiembre 2014) se obtuvieron 1996 firmas, un resultado medio-bajo respecto a los indicadores que se establecieron en la estrategia:

Tabla 4. Leads y visitas únicas de la web Sí me importa

\begin{tabular}{|c|c|c|c|c|c|}
\hline \multirow[t]{2}{*}{ Canal } & \multirow[t]{2}{*}{ Indicador } & \multicolumn{3}{|c|}{ Indicadores prospectivos } & \multirow{2}{*}{$\begin{array}{l}\text { Cumplimiento del } \\
\text { objetivo }\end{array}$} \\
\hline & & Alto & Medio & Bajo & \\
\hline \multirow[t]{2}{*}{$\begin{array}{l}\text { Web Síme } \\
\text { importa }\end{array}$} & Leads & 7.000 & 3.000 & 1.000 & $\begin{array}{c}\text { Medio-bajo } \\
\text { TOTAL: } 1.996 \text { firmas }\end{array}$ \\
\hline & $\begin{array}{l}\text { Visitas } \\
\text { web sin } \\
\text { rebote }\end{array}$ & 14.000 & 7.000 & 1.400 & $\begin{array}{c}\text { Medio-alto } \\
\text { TOTAL: } 9.341 \text { visitas } \\
\text { únicas }\end{array}$ \\
\hline
\end{tabular}

Fuente: elaboración propia a partir de datos de Oxfam Intermón.

4. Comportamiento en medios de comunicación:

A partir del 23 de septiembre, fecha en que se hacía pública la firma de Oxfam Intermón detrás del falso reality show, se esperaba recoger impactos en medios. El resultado fueron 62 impactos en medios digitales. Este objetivo no contaba con indicadores previos.

4 Nota: en el gráfico, las siglas CAC1 y CAC2 hacen referencia a los envíos informativos vía email realizados a la base social de Oxfam Intermón. 


\section{OBSERVACIONES SOBRE LA CAMPAÑA}

A continuación, se destacan algunas observaciones sobre el desarrollo transmedia de la campaña con el fin de identificar aquellos factores que pudieron influir en la consecución de sus objetivos. Asimismo, se plantean opciones alternativas desde el punto de vista de la autora:

1. Embudo de conversión demasiado largo en el tiempo:

Hacer esperar a la audiencia demasiado tiempo se considera el fallo principal de la estrategia. Vivimos en la era de la inmediatez. Solo una audiencia ya fidelizada y con alto interés por un tema (por ejemplo, los fans de una serie de televisión) es capaz de permanecer atenta a la publicación de contenidos durante tanto tiempo. Es por ello que cada fase contó con su propia audiencia.

El problema principal de 3 de10 no fue tanto la longitud del embudo como la imposición de tiempos determinados para resolverlo, lo que hizo que la historia perdiera interés. Una posible solución a este problema podría haber sido proponer experiencias individuales, en las que cada individuo decide el tiempo que dedica a recorrer las diferentes etapas. Es la estrategia utilizada, por ejemplo, por Belén Santa-Olalla en su post Esto NO es un post. Es un rabbithole (2014). Se podría haber planteado, por ejemplo, el visionado del teaser $\mathrm{y}$, tras ello, un registro mediante formulario para poder ver inmediatamente el siguiente vídeo y participar en la votación del reality. A partir de ese momento se podría haber puesto en marcha una estrategia de engagement personalizada vía email y redes sociales, que terminaría con el desvelamiento de la marca Oxfam Intermón y la invitación a la adhesión a la campaña.

Otra ventaja de esta estructura es que no caduca. Al ser una experiencia individual, con unos pequeños ajustes puede seguir disponible indefinidamente para todo aquel usuario que quiera recorrer posteriormente las diferentes etapas de la experiencia. Así, además, se favorecería un aporte continuo de leads para la campaña.

2. El medio se convirtió en el mensaje:

La dificultad de conversión se hizo especialmente patente en Twitter, donde de 1.750 visitas que generó a la web entre el 23 de septiembre y el 05 de octubre, solo 140 finalizaron en firma. El riesgo de usar lenguajes innovadores es que pueden hacer efecto pantalla y ocultar el mensaje principal que se quiere transmitir. La solución pasa por una estrategia bien definida que conduzca a la recepción en el $100 \%$ de los casos del mensaje que se quiere transmitir.

3. El reality no era atractivo para medios:

En una estrategia transmedia cada medio debe hacer lo que mejor sabe hacer. En el caso de los medios de comunicación, era difícil que se fueran a hacer eco de la existencia de un falso reality que, por otro lado, denunciaba un tema ya conocido: los recortes en cooperación. Por ello, se deberían haber diseñado otro tipo de contenidos específicos para medios (testimonios, infografías, entrevistas) que complementaran y ampliaran el universo narrativo, como si de un soporte transmedia más se tratara.

4. Se notaba mucho que era un producto de una ONG:

Para llegar a nuevos públicos hubiera sido necesaria una apuesta más fuerte por el misterio del rabbithole con un producto transgresor que no se relacionara fácilmente con una ONG. Desde el inicio la intriga se dirigió a conocer qué ONG estaba detrás en lugar de ahondar en la temática que se trataba en el reality.

5. Poca implicación de la audiencia:

El usuario tenía un papel muy pasivo dentro de la estrategia. Su participación activa se limitaba a la votación en la web y la firma de la petición. En la escalera de engagement no se tuvieron en cuenta los dos últimos escalones de Forrester, el de los críticos, «que se sienten empoderados para hablar y deci- 
dir, saliéndose incluso de las dinámicas propuestas y expresando su opinión» (Santa-Olalla, 2014), y el de los creadores, «que hacen suya la experiencia, la completan, crean contenido, la expanden con su imaginación y la enriquecen» (Santa-Olalla, 2014). No había por tanto un nivel de prosumición planificada desde la organización.

6. Demasiadas marcas:

Las estrategias transmedia tienen como unos de sus fines reforzar la marca a través de historias atractivas. La campaña Sí me importa en general, cuenta con demasiadas marcas secundarias (Viñetas vida, actuarte, ojoylapiz, comicontour, 9 días en Haití...), que generan ruido e impiden ver la marca principal que hay más allá: Oxfam Intermón. Y 3 de10 es solo una de ellas, por lo que pasa completamente desapercibida.

En todo caso, todos estos aspectos son comprensibles y enriquecedores cuando se está trabajando en una forma nunca antes utilizada por una organización de estas características.

\section{CONCLUSIONES}

De manera cuantitativa se puede concluir que los resultados obtenidos se situaron en su mayoría en un nivel medio. Sin embargo, la ruptura de la lógica lineal de engagement lleva a concluir que fue escasa la cantidad de audiencia que recibió el mensaje de forma adecuada, tal y como se había planificado. Además, el objetivo principal de 3 de10, conseguir adhesiones mediante la firma y la conversión en leads, quedó en un nivel medio-bajo, con solo 1.996 firmas en el periodo de estudio.

Por otro lado, según reflejan los datos, el mayor número de leads obtenidos, unos 1.200, provenían de la base social de Oxfam Intermón; y los perfiles que siguieron el proyecto a través de Twitter fueron personas que expresaban en su biografía su interés previo en temas sociales y de desarrollo.

Por último, todos los materiales se desarrollaron en plataformas presentes en los smartphones, como YouTube y Twitter, pero no se explotaron de forma específica las características del nuevo entorno móvil, como el desarrollo de aplicaciones. Siguiendo el modelo de reality, hubiera sido especialmente atractivo el diseño de una app móvil que permitiera participar y realizar las votaciones, visionar los vídeos y ampliar información, así como plantear algún tipo de experiencia participativa para el consumidor.

En conclusión, no se cumple la hipótesis establecida, ya que la historia planteada no fue recibida de la forma prevista ni consiguió sus objetivos de difusión y sensibilización gracias a las narrativas transmedia. Tampoco se alcanzó a nuevos públicos ni se desarrollaron productos específicos que se adaptaran al uso de los smartphones.

No obstante, desde un punto de vista cualitativo, se puede afirmar que el interés recogido fue muy positivo. El reality, especialmente en su inicio, despertó gran intriga. Las conversaciones en Twitter en esta fase inicial giraron en torno a cuatro vertientes: intriga, «¿de dónde viene? ¿de quién es?»; indignación, «no puede ser»; identificación, «es de una ONG, es un fake, es una campaña viral», y aceptación, «me gusta».

Por ello, por la innovación y el interés que despiertan entre las organizaciones sociales, iniciativas como Sí me importa y 3 de10 son cada vez más necesarias para la renovación de un sector que siente que ya no es el líder de los cambios sociales. Como explicaba Zinnia Quirós, coordinadora de la campaña Sí me importa, en una entrevista para cm3sector.org: «Hay que romper los miedos, no hay que tener miedo a probar cosas nuevas y no hay que tener miedo a equivocarse y a fracasar porque los grandes aprendizajes surgen precisamente del fracaso» (Aguayo, 2015). 


\section{BIBLIOGRAFÍA}

Armañanzas, E. (1993). La acción de los gatekeepers ante los referentes. Communication \& Society. Recuperado el 1 de septiembre de 2016 de: http://www.unav.es/fcom/communicationsociety/es/articulo.php?art id $=237$

Aguayo, A. (2015). Análisis de la campaña Sí me importa - OXFAM Intermon. Cm3sector. Recuperado el 01 de octubre de 2016 de: http://cm3sector.org/2015/11/04/analisis-de-la-campana-si-meimporta-oxfam-intermon/

Balestrini, M. (2011): Lo dijo Henry Jenkins. Sobre los 7 mitos en torno a lo Transmedia. Transmedia. Ideas y textos sobre medios, tecnología y video. Recuperado el 2 de septiembre de 2016 de:

https://transmedial.wordpress.com/2011/11/10/lo-dijo-henry-jenkins-sobre-los-7-mitos-en-torno-alo-transmedia-es-espanol/

Barral, L. M. (2013). Transmedia, Marcas y Gratitud. Inteligencia ética. Consultado el 6 de septiembre de 2016 en: http://inteligenciaetica.com/2013/04/transmedia-marcas-y-gratitud/

Costa, C. y Piñeiro T. (2012). Nuevas narrativas audiovisuales: multiplataforma, crossmedia y transmedia. El caso de Águila Roja (RTVE). Icono 14, 10(2), 102-125.

De Lara, A. y Arias F. (2014). La innovación en la autorreferencia de la televisión española: de la promoción a la transmedialidad. Naukony Przeglad Driennikarski. Recuperado el 01 de octubre de 2016 de: http://naukowy-przeglad-dziennikarski.org/nr/2-2014/4.pdf

Ditrendia (2015). Informe Ditrendia: Mobile en España y en el mundo 2015. Recuperado el 01 de octubre de 2016 de: http://www.ditrendia.es/wp-content/uploads/2015/07/Ditrendia-Informe-Mobileen-Espa $\%$ C3\%B1a-y-en-el-Mundo-2015.pdf

Escudero, J., Delfín L. y Gutiérrez L. (2008). El estudio de caso como estrategia de investigación en las ciencias sociales. Ciencia administrativa, 1, 7-10. Consultado el 12 de octubre de 2016 en: http://www.uv.mx/iiesca/files/2012/12/estudio2008-1.pdf

Gómez D. (2011). Audiencias cada vez más fragmentadas. Bien pensado. Recuperado el 01 de octubre de 2016 de: http://bienpensado.com/audiencias-cada-vez-mas-fragmentadas/

Hernández M. y Grandío M. (2011). Narrativa crossmedia en el discurso televisivo de Ciencia Ficción. Estudio de Battlestar Galactica (2003-2010). Área Abierta, 28, 1-20.

Jenkins, H. (2003). Transmedia Storytelling. Moving characters from books to films to video games can make them stronger and more compelling. Technology Review. Recuperado el 28 de agosto de 2016 de: http://www.technologyreview.com/news/401760/transmedia-storytelling/

Lovato, A. (2015). Periodismo ubicuo. El flujo de trabajo del periodista móvil. En F. Irigay (Ed.), Reflexiones móviles. El periodismo en la era de la movilida (p. 24). Rosario: UNR Editora. Editorial de la Universidad Nacional de Rosario.

Lozano J., Raya I. y López F. (2013). Reyes, espadas, cuervos y dragones. Estudio del fenómeno televisivo Juego de Tronos. Madrid: Fragua.

Marfil-Carmona, R. (2013). Interactividad digital y estrategias narrativas en la publicidad audiovisual de Manos Unidas y Unicef. Historia y Comunicación Social, 18, 178.

Materia Gris (2014). La narrativa transmedia al servicio de causa justas. Blog Materia Gris. Recuperado el 01 de septiembre de 2016 de: http://www.materiagris.es/la-narrativa-transmedia-al-serviciode-causas-justas

Medina, A. y Villarreal, A. (1998). El Reality Show o las emociones como espectáculo. México: Mondino.

Murillo, M. (2014). ¿Qué es transmedia?: entrevista a María Vega. Miluska Murillo. Mobile marketing. Recuperado el 25 de agosto de 2016 de: http://miluskamurillo.com/2014/03/02/que-estransmedia-entrevista-a-maria-vega/ 
Renó, Denis (2012). Narrativa transmedia y la «des-gobernabilidad» periodística. C\&S - São Bernardo do Campo, 34(2), 144.

Renó, D. y Flores, J. (2012). Periodismo Transmedia: Reflexiones y técnicas para el ciberperiodista desde los laboratorios de medios interactivos. Madrid: Fragua.

Renó, D. y Renó, L. (2013). Narrativa trasmedia y mapas interactivos: periodismo contemporáneo. Razón y palabra, 83, 5.

Rodríguez, R. (2013). Contenidos transmedia de las teleseries españolas: clasificación, análisis y panorama en 2013. Communication \& Society. Recuperado el 01 de octubre de 2016 de: http://www.unav.es/fcom/communication-society/es/articulo.php?art_id=513

Rodríguez-Alarcón, L. (2014). ¿Para qué sirve una ONG en España? Blog 3.500 millones. Recuperado el 03 de septiembre de 2016 en: http://blogs.elpais.com/3500-millones/2014/06/para-que-valeuna-ong-en-espa $\% \mathrm{C} 3 \% \mathrm{~B} 1 \mathrm{a} \cdot \mathrm{html}$

Santa Olalla, B. (2014). Esto NO es un post. Es un rabbithole. Innovación audiovisual. Recuperado el 30 de septiembre de 2016 en: http://innovacionaudiovisual.com/2014/12/12/esto-no-es-un-postes-un-rabbithole/

Scolari, C. (2013). Narrativas Transmedia. Barcelona: Deusto.

Tayar, R. (2011). ¿Qué es un embudo (o túnel) de conversión?. Gestión y dirección proyectos web, ecommerce, diseño, análisis y optimización web, conversión, y Rock'n'Roll. Recuperado el 1 de septiembre de 2016 de: http://www.ricardotayar.com/2011/06/20/definicion-embudo-conversion/

Villa, M. I. (2011). Producción cross-media: El caso de Televisió de Catalunya. Tesis Doctoral Universitat Autònoma de Barcelona.

Villena, E. (2013). La narrativa transmedia en el modelo de comunicación de las empresas de moda internacionales: un estudio de caso. Communication Papers. Consultado el 25 de agosto de 2016 en: https://www.academia.edu/8179012/La Narrativa Transmedia en el modelo de comunicaci $\% \mathrm{C} 3 \% \mathrm{~B} 3 \mathrm{n}$ de las empresas de moda internacionales un estudio de caso 